\title{
DESIGUALDADES SALARIALES: UNA NUEVA MIRADA A SU RELACIÓN CON LA EDUCACIÓN Y LOS ANTECEDENTES FAMILIARES
}

\section{Ricardo Nogales Carvajal}

\section{RESUMEN}

Este artículo analiza la desigualdad de oportunidades para acceder a buenos niveles de ingresos en Cochabamba. En lugar de adoptar los enfoques teóricos tradicionales de Mincer y Becker para abordar esta temática, se promueve la adopción del enfoque de Igualdad de Oportunidades de J. Roemer para la identificación de las fuentes de estas desigualdades para identificar las disparidades sociales que pueden ser consideradas como injustas y deben ser el objeto de intervenciones públicas. A partir de los datos de la encuesta realizada por el Foro Regional (2015), analizados a través de un Modelo Generalizado de Ecuaciones Simultáneas, se encuentra que alrededor del $40 \%$ de las probabilidades de acceder a ingresos superiores a tres salarios mínimos depende de antecedentes familiares que están fuera del control de las personas y que limitan los esfuerzos que pueden realizar para adquirir educación. Asimismo, estos antecedentes predeterminan el $26 \%$ de las probabilidades de acceder a ingresos inferiores a un salario mínimo.

Palabras clave: Desigualdades, Retornos Educativos, Modelos Generalizados de Ecuaciones Simultáneas. 